\title{
JUVENILE RHEUMATISM IN LONDON
}

\section{By FRANCIS BACH, N. GRAY HILL, T. WARWICK PRESTON AND CHARLES E. THORNTON}

For the purpose of this paper it is to be understood that the term "juvenile rheumatism" refers to rheumatic disease occurring in children under the age of sixteen. This definition is convenient rather than scientific. It is convenient clinically, in that by far the greater number of initial attacks occur before the age of sixteen, and it has the further practical convenience that up to this age children come within the scope of the provisions of the Education Acts, whereby special facilities are available for treatment and supervision. Nevertheless it must be borne in mind that rheumatism of the juvenile type does occur in individuals above the age of sixteen, and that rheumatoid types of the disease resembling those found in adults sometimes occur in children. It should also be understood that the authors have restricted themselves to summarising facts connected with the clinical and sociological aspects of the disease; no attempt has been made to discuss or summarise the results of recent bacteriological or biochemical research. Though this work has revealed interesting and suggestive facts, further progress must be made before they can be applied by the clinician or influence the public health administrator in his endeavours to reduce the incidence or minimise the direful effects of juvenile rheumatism.

For practical purposes juvenile rheumatism may be classified according to its manifestations into:

(a) Acute rheumatic " fever," usually involving the joints.

(b) Subacute rheumatism involving the joints, muscles, and fibrous tissues.

(c) Acute rheumatic carditis and /or pericarditis.

(d) Insidious carditis developing with or without evidence of associated peripheral rheumatism.

(e) Chorea.

All these forms of the disease, although differing widely in some respects, exhibit two tendencies in common-a tendency to recur repeatedly and a tendency to cause permanent cardiac 210 
damage. Furthermore, a combination of one or more of these manifestations may, and often does, occur in the same child.

It cannot be too strongly emphasised that acute rheumatism with its swollen joints, the muscle and joint pains and fatigue syndromes of childhood, the chorea of childhood, and the acquired forms of heart disease are all manifestations of the same systemic disease, which may run a course extending over a period of many years. It is indeed but too true that, in the words of Cheadle, "the history of rheumatism may be the history of a whole childhood," and he might have gone even further and said " the history of a whole life."

\section{Incidence of Juvenile Rheumatism in London}

Juvenile rheumatism in its various guises, together with its cardiac sequelæ, is the most common single cause of persistently irregular school attendance. The returns of the school attendance department of the London County Council for 1936 showed that of children out of school for three months or more on account of illness, the rheumatic diseases accounted for 26.7 per cent. of the total number. Again, rheumatic children form about one-half of the total number of children in attendance at schools for the physically defective. Medical supervision and treatment and the provision of special education for the rheumatic children of London involves an annual charge on public funds of approximately $£ 200,000$, and about 20 per cent. of rheumatic children have suffered a degree of cardiac damage which renders them unfit, on leaving school, to undertake any but the lightest of occupations.

\section{Estimated Number of Rheumatic Children in London}

To estimate the actual number of children in London suffering from rheumatic infection or its sequelæ is not easy. The following figures are in the nature of an approximation. The actual number of rheumatic children is undoubtedly considerably greater than the total here obtained.

Number of Rheumatic Children under Supervision or Treatment, JUNE, 1938

$\begin{array}{lllll}\text { Number under supervision by school doctors } & \ldots & \ldots & \mathbf{2 , 6 3 2}\end{array}$ Number under supervision at supervisory centres $\quad \ldots \quad \ldots \quad \ldots \quad \mathbf{5 , 1 6 0}$

Number under treatment in the Council's rheumatism units $\ldots . \quad 872$

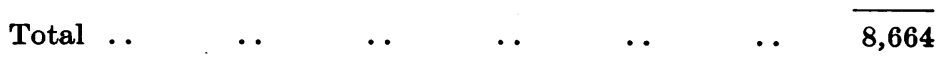


This total represents the number of "active" or recently active cases of juvenile rheumatism. It does not include a very large proportion of rheumatic children between fourteen and sixteen years of age who have left school; neither does it include a large number of children still at school who have been discharged, for the time being at least, from supervision. A better idea of the real extent of the prevalence of the disease is obtained from the number of children whose records are found in the card index kept in the Public Health Department. In June, 1938, this number was 22,800 . All these children are known to have suffered or to be suffering from rheumatic infection. The estimated child population of London-i.e., children up to the age of fifteenwas in 1935 approximately 878,000 , and it is tending to diminish. Taking, however, this figure of $878,000,22,800$ rheumatic children represents an incidence of rheumatism in approximately 2.6 per cent. of the child population.

\section{InCRease or Decrease in the OCcurRence of Juvenile Rheumatism}

At present it is difficult to be sure whether or not any diminution in the prevalence of juvenile rheumatism is occurring. During the last ten years greatly increased provision has been made in London for the treatment and supervision of rheumatic children, and it is certain that the yearly increase during this period in the number of children referred for treatment under the London County Council's Rheumatism Scheme is more a reflection of the increased provision made than an indication of an increasing prevalence. Indeed, there are signs that no notable increase is occurring. About the middle of 1935 the scheme was reviewed and additional beds provided in the special hospitals in numbers sufficient, it was estimated, to meet all demands. The experience of the last three years shows that the number provided is adequate approximately to present needs. The number of applications received for admission to these special "rheumatism units" has shown a tendency to become stabilised at about 2,000 to 2,500 per annum.

\section{Change in Type}

It is of importance to ascertain, if possible, if any evidence exists tending to indicate a decreasing virulence of the disease either in connection with its acute phases or with regard to the 
incidence and severity of its cardiac complications. If such a decrease in virulence can be shown to be occurring, it is a fact hardly less in importance than an actual decrease in the general incidence of the disease. In so far as the acute phases are concerned, all clinicians agree that the type of case characterised by acutely swollen joints, sour sweats, and severe prostration is now rarely seen. This change of type has no doubt been brought about partly by earlier and more intensive treatment in the acute stage, and in part is due to a gradual increase in the diseaseresisting power of the child population. For this latter factor improved social conditions and careful medical supervision during school life are chiefly responsible. It would, however, afford little ground for satisfaction if, associated with this decrease in severity of acute rheumatism, there was no corresponding decrease in the amount of rheumatic heart disease. Whether a child suddenly becomes a cardiac cripple following an attack of acute rheumatism or chorea, or gradually becomes a cardiac cripple following a milder subacute attack, the result is equally disastrous. The medical inspection of school children, by revealing the presence of an enormous amount of unsuspected rheumatic cardiac disease, showed that the milder types of rheumatic disease were likely to be no less inimical to the prospects of a useful and prolonged life than were the more acute types of attack which formerly were common. The percentage of children found by the school doctors to be suffering from rheumatic heart disease has, however, decreased from 2.0 per cent. in 1926 to 0.77 per cent. in 1937. It can therefore be asserted with a certain degree of confidence that even if there be no notable decrease in the incidence of rheumatic infection, there has been a definite decrease both in the virulence of the acute form of the disease and in the frequency and severity of the cardiac complications.

\section{Onset Age of Juvenile Rheumatism and Chorea}

An analysis was made of 1,000 cases admitted to the Council's rheumatism units during the first six months of 1937. The greatest care was taken to ascertain the age at onset of the initial attack. Diagram 1 shows:

(a) Age at onset of all cases (both sexes).

(b) Age at onset of muscular or articular rheumatism (both sexes).

(c) Age at onset of chorea (both sexes). 
In general the graphs indicate that quite an appreciable number of cases of juvenile rheumatism occur in children under the age of five, and that there is a gradually increasing susceptibility up to the age of nine in the case of chorea, and up to the age of eleven in the case of articular or muscular rheumatism. It is, however, exceedingly rare to find cases in which the onset

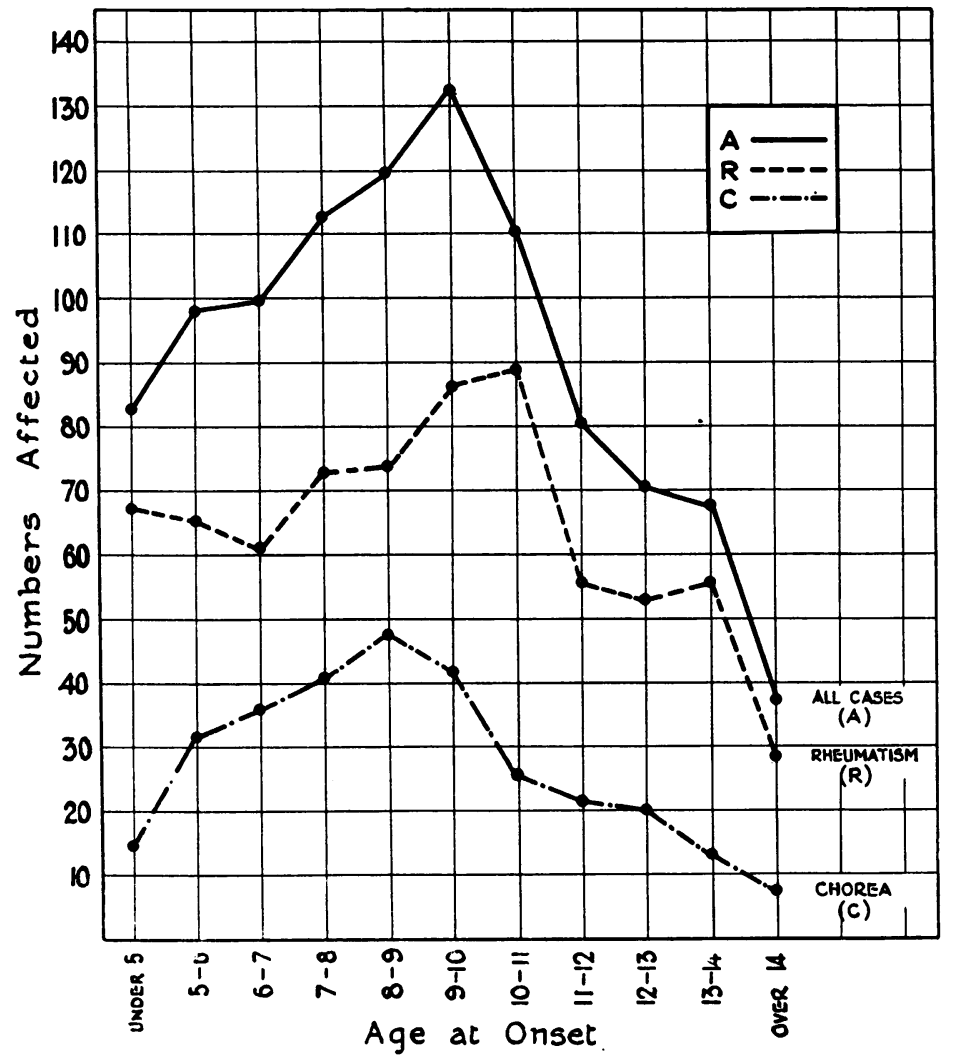

Diagram 1.-Showing Ages at Onset in 1,000 Cases of Rheumatism and Chorea.

occurred in children below the age of three. After the age of eleven it would seem that susceptibility to both diseases rapidly diminishes until at the age of fourteen the "risk" appears to be only about half what it was at the age of five. The dangerous age for children in regard to rheumatic infections lies between five and twelve years. 


\section{Influence of Age Incidence on Prognosis}

An attempt was made to discover if the age at onset of rheumatic infection had any influence on the prognosis of the disease. With this object in view the authors endeavoured to trace the after-histories of two series of cases. The first series of 200 was taken from children treated in the rheumatism unit at Queen Mary's Hospital during 1927; the second series from children treated in 1932. Unfortunately it was only possible to trace in the two series together a total of 242 children. This relatively small proportion traced reduces the validity of deductions made therefrom, but the results are nevertheless interesting. As the numbers are small the two series have been tabulated together.

Table I.-Condition in 1937 of 242 Patients treated at Queen MaRY's (L.C.C.) Hospital IN 1927 aNd 1932

\begin{tabular}{|c|c|c|c|c|c|c|c|c|c|}
\hline \multirow{2}{*}{ Age Classification. } & \multicolumn{3}{|c|}{ Alive and Well. } & \multicolumn{3}{|c|}{ Invalid. } & \multicolumn{3}{|c|}{ Deceased. } \\
\hline & Boys. & Girls. & Total. & Boys. & Girls. & Total. & Boys. & Girls. & Total. \\
\hline $\begin{array}{l}\text { Aged } 5 \text { years and } \\
\text { under } \\
\text { Aged } 6-9 \text { years } \\
\text { Aged } 9-12 \text { years } \\
\text { Over } 12 \text { years .. } \\
\text { Age at onset un- } \\
\text { known }\end{array}$ & $\begin{array}{r}8 \\
22 \\
17 \\
10 \\
-\end{array}$ & $\begin{array}{r}10 \\
30 \\
32 \\
16 \\
\\
3\end{array}$ & $\begin{array}{r}18 \\
52 \\
49 \\
26 \\
\\
3\end{array}$ & $\begin{array}{r}2 \\
4 \\
2 \\
1 \\
-\end{array}$ & $\begin{array}{r}10 \\
19 \\
8 \\
4 \\
\\
1\end{array}$ & $\begin{array}{r}12 \\
23 \\
10 \\
5 \\
1\end{array}$ & $\begin{array}{r}1 \\
8 \\
4 \\
4 \\
- \\
\end{array}$ & $\begin{array}{r}3 \\
13 \\
5 \\
2 \\
\\
3\end{array}$ & $\begin{array}{r}4 \\
21 \\
9 \\
6 \\
3\end{array}$ \\
\hline Totals & 57 & 91 & 148 & 9 & 42 & 51 & 17 & 26 & 43 \\
\hline
\end{tabular}

It would appear that those who are attacked by rheumatism during the early years of school life fare the worst. The numbers of children studied are too small to allow any definite conclusions to be drawn, but it would seem that the chances of cardiac damage diminish as the heart takes on the more adult form. As is shown in the table, there are 130 children under nine years of age who were treated, and at the time of this investigation sixty of these were either dead or invalided, leaving only seventy to be classed as alive and well. On the other hand, of the 105 children over nine years of age only thirty are dead or invalided and seventyfive are known to be enjoying good health. The earlier the age of onset, the worse would seem the prognosis for the rheumatic child. 


\section{Sex InCIDence}

The greater susceptibility of girls to rheumatic infection is universally recognised. All collected statistics are in agreement on this point. The relative number of boys and girls admitted during 1934, 1935 and 1936 to the rheumatism units of the London County Council may be quoted.

$\begin{array}{lllll}\text { Number of boys admitted } & \ldots & \ldots & \ldots & \mathbf{2 , 0 6 9} \\ \text { Number of girls admitted } & \ldots & \ldots & \ldots & \mathbf{2 , 7 0 5}\end{array}$

Using these figures, the ratio of the number of boys affected to the number of girls is almost exactly $3: 4$.

An analysis of 3,683 children attending rheumatism supervisory centres gave a similar result.

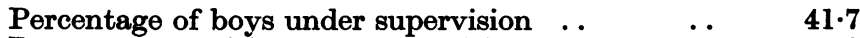

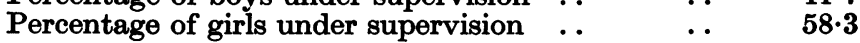

These figures indicate the ratio of boys affected to girls affected as being equivalent to $3: 4 \cdot 2$-a ratio which is in close agreement with that obtained from the hospital figures.

\section{Sex Incidence related to Type of Case}

The preponderance of girls affected was greatest in the milder type of case-i.e., cases of persistent subacute rheumatic pains with no definite cardiac involvement. This is shown by the following figures taken from statistics of the supervisory centres:

Table II.-Sex Incidence of the Various Types of Case

\begin{tabular}{|c|c|c|c|c|}
\hline Sex. & $\begin{array}{c}\text { Cases with } \\
\text { History of } \\
\text { Acute } \\
\text { Arthritis. }\end{array}$ & $\begin{array}{l}\text { Cases of } \\
\text { Definite } \\
\text { Chorea. }\end{array}$ & $\begin{array}{l}\text { Cases of Ac- } \\
\text { quired Cardiac } \\
\text { Disease, but } \\
\text { with no } \\
\text { Definite } \\
\text { Rheumatic } \\
\text { History. }\end{array}$ & $\begin{array}{l}\text { Mild Subacute } \\
\text { Rheumatism } \\
\text { or Chorea } \\
\text { without } \\
\text { Cardiac } \\
\text { Involvement. }\end{array}$ \\
\hline $\begin{array}{l}\text { Boys } \\
\text { Girls }\end{array}$ & $\begin{array}{l}42 \cdot 8 \text { per cent. } \\
57 \cdot 2 ",\end{array}$ & $\begin{array}{l}\text { 42.8 per cent. } \\
57 \cdot 2 "\end{array}$ & $\begin{array}{l}\text { 46.0 per cent. } \\
54.0 " \text { " }\end{array}$ & $\begin{array}{l}39.0 \text { per cent. } \\
61.0 " \text { " }\end{array}$ \\
\hline
\end{tabular}

Influence of Sex on the Incidence of Cardiac Involvement

Considering the sexes separately, it is found that cardiac involvement occurs slightly more frequently in boys than in girls. In the previously quoted 4,774 admissions to rheumatism units, 
of the boys $40 \cdot 2$ per cent. had signs of cardiac involvement, whilst in only 37.4 per cent. of the girls was the heart affected. Similarly, when discharged from hospital permanent cardiac damage is found more frequently in boys than in girls. An analysis of 1,152 cases discharged showed that in boys the heart had become permanently damaged in 38 per cent. of cases. Only 33.3 per cent. of the girls were similarly affected. Two possible explanations of this preponderance of cardiac involvement in boys may be advanced. The first suggests that it is correlated with the somewhat greater physical activity which boys exhibit, and their disinclination to accept the rôle of invalid until compelled to do so. Alternatively, it may be that the greater incidence of cardiac involvement in boys is related to their apparently greater susceptibility to rheumatic infection between the ages of six and seven. It has already been pointed out that the earlier the age of onset, the greater the risk of cardiac damage. Possibly both explanations may be to a certain extent true.

While in hospital more boys than girls die of cardiac failure, and this fact has been quoted as indicating that a more severe type of carditis occurs in the young male. When, however, a follow-up investigation was carried out, there was no appreciable difference found in the mortality figures for the two sexes, and, moreover, the invalidity figures for girls were appreciably higher than in the case of boys.

\section{The Relationship of Juvenile Rheumatism to Social ENVIRONMENT}

It is commonly held that rheumatism is a disease of the children of the poor and is comparatively rarely met with amongst the children of the more prosperous classes. $A$ priori it is reasonable to suppose that this is likely to be true. If, as is at least probable, the disease is due to an infection, it should naturally occur most frequently amongst the children of the poor, living as they often do under conditions of overcrowding, sometimes in damp tenements or basement dwellings.

Such unfavourable surroundings, possibly in a proportion of cases associated with insufficient or improper food, will obviously tend to render children a more easy prey to any form of infection, and, once infected, render the outlook more unfavourable. 


\section{Difficulties in the Obtaining of Reliable Statistics}

When, however, an attempt is made to evaluate this preponderance (assuming it exists) difficulties at once arise. Rheumatism is not (except in a negligible number of districts) " notifiable." Indeed, it is a difficult disease to include in any Notification Act, owing to the indefinite character of many of its manifestations. Consequently, our knowledge of its prevalence is in the main obtained by the analysis of hospital statistics or the statistics of the school medical services. Deductions from hospital statistics always tend to be vitiated by the fact that the information obtained relates in the main to those who are in the habit of relying on hospitals for medical treatmenti.e., the poorer classes of the community; in these statistics the poor always preponderate. This is particularly the case where the milder forms of rheumatism are concerned. The poor take their children to the hospital out-patient department or rheumatism supervisory centre; the more prosperous seek the advice of their family doctor. Since for detailed information we are almost entirely dependent on these hospital and supervisory centre statistics, it follows that in one section of the community almost every case of juvenile rheumatism is noted and supervised, whilst for the more prosperous classes we have only very scanty information. The above points must be remembered in considering how much light is thrown on the question by the subjoined figures:

Table III.-Home Environment of 1,000 ChildRen admitted to the Council's Rheumatism Units, Jandary to June, 1937

\begin{tabular}{|c|c|c|c|c|}
\hline Disease. & & $\begin{array}{l}\text { Percentage of } \\
\text { Homes classed } \\
\text { as Very Good. }\end{array}$ & $\begin{array}{c}\text { Percentage } \\
\text { classed as } \\
\text { Average. }\end{array}$ & $\begin{array}{l}\text { Percentage } \\
\text { classed as } \\
\text { "Poor." }\end{array}$ \\
\hline $\begin{array}{l}\text { Rheumatism } \\
\text { Chorea .. }\end{array}$ & $\begin{array}{l}\ldots \\
\ldots\end{array}$ & $\begin{array}{l}1 \cdot 0 \\
0 \cdot 4\end{array}$ & $\begin{array}{l}55 \cdot 2 \\
23 \cdot 4\end{array}$ & $\begin{array}{r}14 \cdot 0 \\
6 \cdot 0\end{array}$ \\
\hline Totals . & . & $1 \cdot 4$ & $78 \cdot 6$ & $20 \cdot 0$ \\
\hline
\end{tabular}

The table shows that 20 per cent. of rheumatic children came from very poor homes, but, on the other hand, it is quite possible that if careful enquiry were made into the home environment of 1,000 non-rheumatic children from the same 
social class, practically the same percentage of unsatisfactory conditions would be found. More significant, perhaps, is the fact that in only 1.4 per cent. of the children could the homes be classified as "very good," but here again the warning as to the possibility of rheumatic children who live in very good homes being privately treated, and thus not appearing in these figures, must be remembered.

Cases in which there was evidence of rheumatism being brought on by gross neglect, etc., were extremely few.

With a view to ascertaining if a bad home environment had an unfavourable influence in connection with the supervention of cardiac complications or the occurrence of relapses, an analysis was made of 1,500 admissions to rheumatism units. The results (see Table IV.) seem to show that rheumatic children coming from damp or overcrowded homes run no greater risk, so far as cardiac involvement is concerned, than do children more fortunately situated; neither is the slightly greater percentage of recurrences which they exhibit large enough to be significant.

Table IV.-Home Environment of Rheumatic Children and its Relation to Cardiac Complications and Relapses (1,500 Cases)

\begin{tabular}{|c|c|c|c|c|c|}
\hline \multirow{2}{*}{ Type of Dwelling. } & \multirow{2}{*}{$\begin{array}{c}\text { Number } \\
\text { of } \\
\text { Children. }\end{array}$} & \multicolumn{2}{|c|}{$\begin{array}{c}\text { Cardiac } \\
\text { Involvement. }\end{array}$} & \multicolumn{2}{|c|}{ Relapses. } \\
\hline & & Number. & $\begin{array}{l}\text { Percent- } \\
\text { age. }\end{array}$ & Number. & $\begin{array}{l}\text { Percent- } \\
\text { age. }\end{array}$ \\
\hline $\begin{array}{lll}\text { Average } & \ldots & \ldots \\
\text { Damp } & \ldots & \ldots \\
\text { Overcrowded } & \\
\text { Damp and overcrowded }\end{array}$ & $\begin{array}{r}959 \\
206 \\
246 \\
89\end{array}$ & $\begin{array}{r}416 \\
83 \\
108 \\
38\end{array}$ & $\begin{array}{l}43 \\
40 \\
44 \\
42\end{array}$ & $\begin{array}{r}474 \\
113 \\
138 \\
47\end{array}$ & $\begin{array}{l}49 \\
54 \\
56 \\
53\end{array}$ \\
\hline Totals .. & 1,500 & 645 & 43 & 772 & 51 \\
\hline
\end{tabular}

\section{Distribution of Juvenile Rhedmatism in London}

The distribution, as indicated by the number of nominations for institutional treatment per 1,000 elementary school children in the various London boroughs, seems to coincide fairly closely with density of population, and therefore is, in the main, heaviest in the poorer and more overcrowded boroughs. In general, the heaviest incidence falls on the boroughs immediately adjoining the south bank of the Thames. These are densely populated areas, and perhaps their situation on the river flood-plain has 
a contributory influence. Wandsworth on the west and Greenwich and Woolwich on the east exhibit a lower incidence, and in these boroughs the population density per acre is considerably less. On the north side of the Thames the greatest incidence falls on Finsbury, Shoreditch, Bethnal Green, Stepney and Stoke Newington - all densely populated areas.

\section{Seasonal Incidence of Juvenile Rheumatism}

Juvenile rheumatism exhibits a very definite seasonal incidence. An analysis of the months of onset of 1,500 cases admitted to the rheumatism units during 1935 showed the disease to be most prevalent during the period October to February-i.e., during the coldest, darkest and most humid months of the year. A definite relationship would appear to exist between the prevalence of rheumatism and the amount of sunshine, the mean air temperature and the percentage atmospheric humidity. A low mean air temperature, a small amount of sunshine and a high percentage of humidity, when occurring simultaneously, seem to be associated with a high incidence of rheumatic infection. Conversely, plentiful sunshine combined with a high mean temperature and low humidity are associated with a very obvious fall in the number of rheumatic cases. These facts are shown graphically in Diagram 2.

\section{Modes of Onset of Rheumatism and Chorea}

The following figures show the modes of onset in 1,000 cases admitted to the rheumatism units during the first half of 1937 :

Table V.-Modes of Onset of Rheumatism and Chorea (1,000 CASES)

\begin{tabular}{|c|c|c|c|}
\hline Mode of Onset. & $\begin{array}{c}\text { Rheumatism, } \\
\text { Acute and } \\
\text { Subacute. }\end{array}$ & Chorea. & Total. \\
\hline 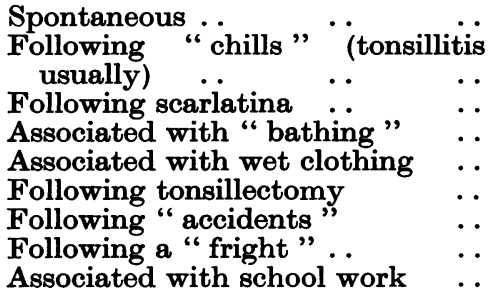 & $\begin{array}{r}621 \\
47 \\
15 \\
3 \\
7 \\
7 \\
1 \\
3 \\
-\end{array}$ & $\begin{array}{r}257 \\
3 \\
6 \\
1 \\
6 \\
10 \\
9 \\
4\end{array}$ & $\begin{array}{r}878 \\
50 \\
21 \\
3 \\
8 \\
13 \\
11 \\
12 \\
4\end{array}$ \\
\hline Totals & 704 & 296 & 1,000 \\
\hline
\end{tabular}


The great majority of cases of rheumatism appear to have a "spontaneous" onset. In acute cases the parent usually

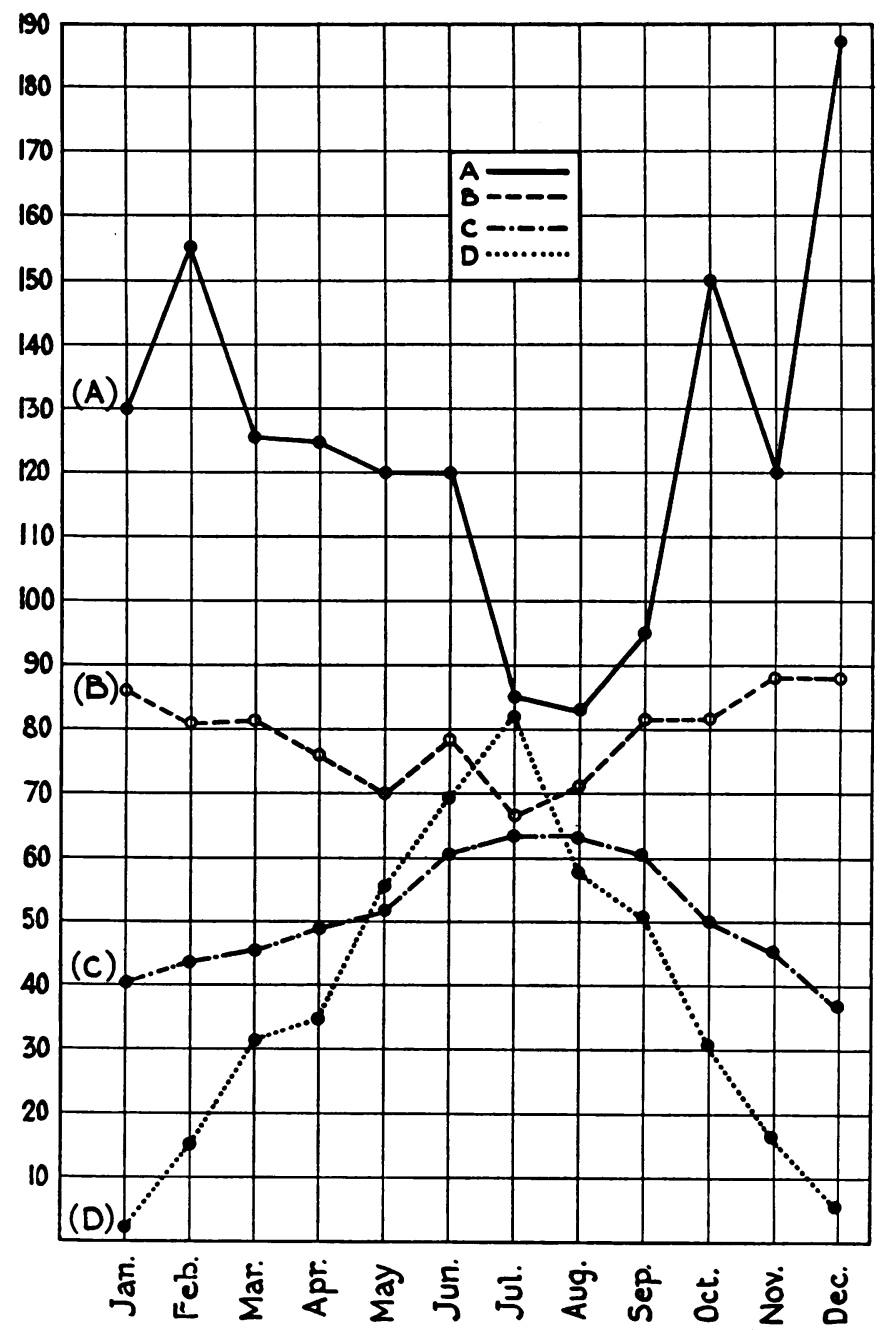

Diagram 2.-Seasonal Incidence of Juvenile Rheumatism.

(A) Months of onset of 1,500 cases of rheumatic infection (including chorea). (B) Monthly percentage of atmospheric humidity. (C) Mean monthly air temperature. (D) Average number of hours of sunshine per day each month multiplied by 10 .

asserts that the child was quite well prior to the attack. In a small proportion of cases the attack is ascribed to a "chill," 
which, on enquiry, is usually found to have been an attack of tonsillitis. The number of cases attributed to bathing, paddling or wet clothing is almost negligible.

\section{Trauma, School Work and Chorea}

Special enquiries were made in cases of children suffering from chorea as to the possible association of the attack with mental or physical "shock" or with school work. The figures given in the above table show that in twenty-five instances (i.e., in almost exactly 8 per cent.) the attack was associated with mental or physical trauma.

It has often been suspected that attacks of chorea in children may be induced by school work or the strain of preparing for examinations. There is little direct evidence to support this view. Of the 296 cases analysed, in only four cases was the attack attributed to school work. In twenty-two cases found in secondary school children, the cause in four instances was asserted to be "worry" regarding examinations. This is a high proportion, but, on the other hand, the small total number of cases of chorea found suggests that the incidence of chorea in secondary school children is particularly low.

\section{Rheumatic Pains}

A detailed analysis made by Dr. T. W. Preston of 257 rheumatic children attending his supervisory centres led him to the following conclusions, which are of special interest in connection with insidious carditis and complaints of rheumatic pains:

(i) Whereas a long history of aching limbs is common in children who show nothing objective, on the other hand children with severe rheumatic carditis often make but little complaint of pain.

TABLE VI

\begin{tabular}{|c|c|c|c|c|}
\hline & & $\begin{array}{l}\text { Cases of } \\
\text { Carditis. }\end{array}$ & \begin{tabular}{c|} 
Insidious \\
Rheumatism \\
without \\
Carditis.
\end{tabular} & $\begin{array}{c}\text { Doubtful } \\
\text { Rheumatism. }\end{array}$ \\
\hline $\begin{array}{l}\text { Constant complaints } \\
\text { Fairly frequent complaints } \\
\text { Infrequent complaints } \\
\text { No complaints . . }\end{array}$ & $\begin{array}{l}\ddot{ } \\
\ddot{*} \\
\cdots\end{array}$ & $\begin{array}{lc}10 & \text { per cent. } \\
32 & " \\
58 & "\end{array}$ & $\begin{array}{l}7 \text { per cent. } \\
50 " \\
43 " \\
\end{array}$ & $\begin{array}{l}6 \text { per cent. } \\
48 \text { " } \\
46 \quad "\end{array}$ \\
\hline
\end{tabular}


Similar observations were made in a previous investigation; then it was also noted that frequent complaints of aching limbs were uncommon in children with a former history of acute rheumatism.

(ii) The development of carditis in the whining child who, according to the mother, has had rheumatism "all its life" seems to be extremely rare.

(iii) The more carefully one investigates the histories of cases of " insidious carditis," the fewer become the cases which are truly "insidious." If one classes a case as "insidious " merely because the parent says that the child has never had acute rheumatism or chorea, the number will be large; but on close enquiry many of these will be found to have had a mild illness which was undoubtedly subacute rheumatism.

(iv) The sudden development of a stiff joint in a child is extremely likely to be rheumatism; some of these cases have masqueraded as "sprains," and this diagnosis should not be accepted in the absence of a convincing history of trauma.

(v) Unfortunately, in the absence of a reliable biochemical or serological test there is no definite means of diagnosing rheumatism with certainty, and it is necessary to take a cautious attitude with a child complaining of aching limbs. After a careful examination, however, and a reasonable period of observation, there would seem to be no sound reason for advising a life of semi-invalidism merely on account of "growing pains."

\section{Treatment of Juvenile Rheumatism: The London County Council's Rheumatism Scheme}

In London the beginning of an organised effort to combat the menace of juvenile rheumatism dates from the latter end of 1926, when a special unit of sixty beds was established by the Metropolitan Asylums Board at Queen Mary's Hospital, Carshalton. For several years a feeling had been steadily growing that a disease which, clinically, in its smouldering course much resembled tuberculosis should be dealt with on similar linesi.e., by early and prolonged rest followed by a period of close supervision. Although administrative action had been taken with regard to tuberculosis as early as 1908, interest in the problem of rheumatism in children was not really aroused (although a good deal of pioneer work had been done in America) until about 1923, when the question was discussed at the annual meeting of the British Medical Association. Following this, Sir George Newman, in his annual report to the Board of Education for 1924, and the Invalid Children's Aid Association, in a memorandum in 1925, urged the necessity for the provision of more institutional accommodation for rheumatic children-where it 
would be possible to continue the child's education during the latter part of its enforced stay in hospital.

A comprehensive scheme was therefore organised, under the direction of Dr. C. J. Thomas, one of the Council's Senior Medical Officers, for the treatment and supervision of rheumatic children under the age of sixteen, having in view:

(a) A gradual increase in the accommodation in special rheumatism units until beds in sufficient number were available to provide for an average period of treatment of six months for all children showing signs of active disease.

(b) The establishment of Rheumatism Supervisory Centres for the purpose of early diagnosis of doubtful cases and supervision of quiescent cases.

(c) The establishment of an alternative system of supervision by the school doctors.

(d) Investigation and amelioration, if necessary and possible, of the child's home environment.

(e) The central co-ordination of the various branches of the scheme.

(a) The Special Rheumatism Units.-The present accommodation available amounts to 650 beds for acute and subacute cases, with an additional 250 for doubtful or extremely mild cases or cases of rheumatic heart disease in which a short period of convalescence for the purpose of cardiac rest is desirable.

These rheumatism " units" (with one exception) are recognised by the Board of Education as "hospital schools," and are staffed by qualified teachers.

(b) Establishment of Rheumatism Supervisory Centres.The provision of such centres was agreed to by the London County Council in February, 1928, and a few weeks later the first two centres were opened. This number was quickly increased, until at the present time twenty-one such centres are in existence, and in December, 1938, 5,160 children were under supervision.

The purpose of these centres is:

(i) To keep under periodical medical supervision children known to have suffered from an attack of any form of rheumatic infection.

(ii) To keep under observation children suffering from mild rheumatic symptoms and to advise parents as to the general care of such children.

(iii) To advise parents, teachers and others concerned of any special modifications which are desirable in connection with the 
education of the rheumatic child-e.g., recommendations regarding restriction of physical exercises, playground activities or " homework" may be made; or it may be advised that a transfer to a school for physically defective children is desirable.

(iv) To ascertain the home conditions of children attending the centre, and to take such action as may be necessary or possible to improve an unfavourable environment.

(v) To act in a specialist advisory capacity to school doctors and others who may refer doubtful cases for diagnosis.

In particular it is to be noted that the Rheumatism Supervisory Centre, as its name implies, is not a centre for treatment; its functions are supervisory and advisory.

(c) Supervision by the School Medical Service.-In many instances supervision at the Rheumatism Supervisory Centres is considered either not necessary or not desirable. For such cases arrangements are made for the child to be periodically reported on by the school doctor in the ordinary course of his visits to the school. Under this procedure the child is usually seen at intervals of about six months. In December, 1938, 2,632 children were thus being kept under observation.

(d) The Home Environment.-A report on the home conditions of each child admitted to a unit is obtained, a Care Committee worker visiting the child's home for this purpose. Should the report contain evidence of the presence of unsatisfactory conditions, the Borough Medical Officer of Health is informed. In 1938 1,744 such reports were sent in by Care Committee workers, and in $\mathbf{4 3 4}$ instances premises were reported to the local Medical Officers of Health for further investigation. The assistance of the Medical Officers of Health and the Care Committees is invaluable.

(e) Central Co-ordination.-The responsibility of co-ordinating the various parts of the Rheumatism Scheme in London rests with the Supervising Medical Officer. He is responsible for:

(i) The control of the admissions of cases to the special rheumatism units.

(ii) Making arrangements for the supervision of children after they have been discharged from the units.

(iii) Deciding on the most suitable type of school for the child after its discharge from a unit.

(iv) The general supervision of the work of the rheumatism supervisory centres. 
(v) Effecting liaison between the medical officers doing work in connection with the various subdivisions of the scheme, and also between those working within the scheme, and others who, for one reason or another, may be interested in the children under treatment.

(vi) Supervision of registration and statistical work in connection with the scheme, and the preparation of an annual report.

Rheumatism Scheme: Diagrammatic Representation of Method of dealing with Rheumatic Children referred to the Council FOR Institutional Treatment UNDER the Scheme

(The figures refer to the number of children dealt with during 1936.)

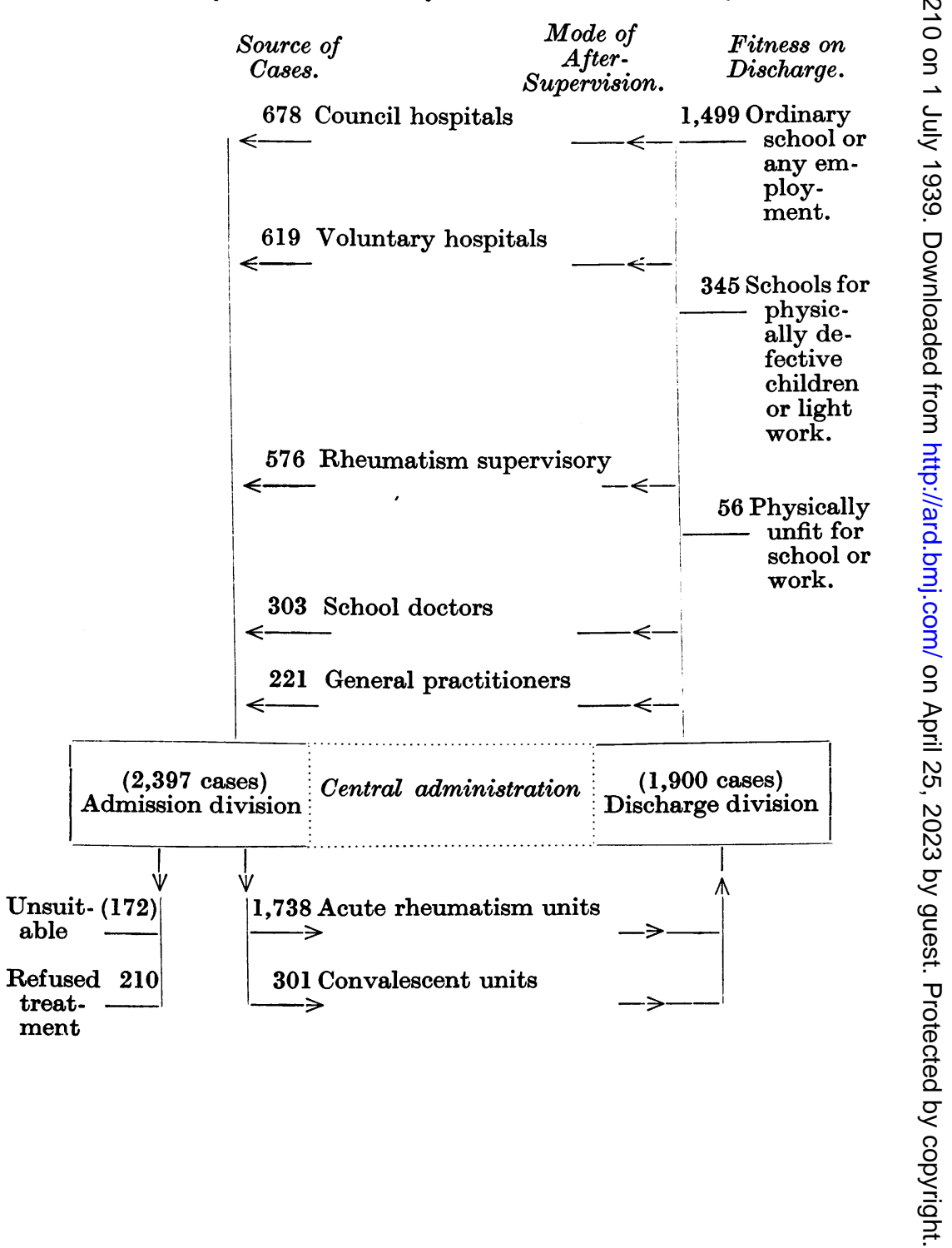


Control of Admissions to the Rheumatism Units.-When application is made for the admission of a child to a rheumatism unit, the case is examined by a medical "referee." A detailed report and recommendation is prepared, and this is then used as a guide in the allocation of the case to the most suitable unit. A copy of this report is sent to the Medical Superintendent of the unit. In 1938, 2,230 such applications for treatment were received.

Arrangements for SUpervision afTer Discharge from the Rheumatism Units and Decision as to Type of EducaTION.-When a child is discharged, a report is sent to the Supervising Medical Officer giving details of the child's progress whilst in hospital and its condition on discharge. This report is considered, and a decision is made as to the type of school the child should attend. In case of doubt a special medical examination is arranged. A copy of the report is supplied to the doctor or hospital who originally nominated the child for treatment. Should the child be over school age, a report is sent to the AfterCare Association indicating any special precautions which may be desirable, and advising as to a suitable type of work.

Summary.-The London County Council's Rheumatism Scheme, which has been evolved for dealing with the problem of juvenile rheumatism and its sequelæ, is probably the most comprehensive of its kind in existence. It provides facilities for early diagnosis. It ensures that, for all cases needing it, an adequate period of institutional treatment is available. It includes arrangements for the education of the convalescent child whilst still in hospital, and for the constant medical supervision of every rheumatic child up to the age of leaving school. Nor does its influence then cease. With the collaboration of the After-Care Association for Blind, Deaf and Crippled Children (the latter class including " cardiac cripples") supervision continues, and work is found of a kind which can be safely undertaken by those suffering from the results of an attack of the disease.

\section{Treatment}

REST.-That rest is an essential factor in the treatment of acute rheumatism all are agreed, but there are differences of opinion as to the length of time this form of treatment should take and as to the best methods which can be employed to 
obtain both rest for the body and rest for the mind. The older physicians were content to nurse their acute rheumatic patients in bed for a period of from three to six weeks, and then, if the temperature was normal, to allow them to resume their ordinary daily life, or to recommend a holiday or a short stay in a convalescent home, the entire course of treatment, including the convalescent period, taking three months or even less.

In the London County Council's hospitals rest under good hygienic conditions has been the mainstay of the treatment. Many of the rheumatic patients are at least six months in the hospital, and some of them stay for longer, the average period of stay in the acute and subacute units being just under seven months. The actual procedure is, of course, varied, according to the stage that the treatment has reached when the patient is admitted, and is also modified to some extent according to the progress and general clinical behaviour of the case, but as a rule every patient is nursed in bed for at least three months after admission. At first the child is kept flat, except for a pillow, and then by degrees allowed to sit up for strictly specified periods, which are gradually lengthened. Absolute recumbency is not entirely satisfactory, and at times defeats its own object. The rheumatic child, once the temperature has settled, feels perfectly well, and is often of a rather nervous and excitable disposition, and a prolonged period of forced recumbency proves a strain on the patient, and rest and strain are diametrically opposed. Rest must be natural, not forced, and the child must be at peace with its surroundings. Anything that can be done to keep the children happy and occupied without exerting them is of the greatest value and to be encouraged; nothing but harm is done by confining children to bed, and allowing them to become bored, dissatisfied and introspective.

At Queen Mary's Hospital, Carshalton, the treatment tends to follow these lines, though certain modifications have to be made for individual cases. If all has gone well with the rheumatic patients after being in bed for about three months, they are allowed up by degrees. At first they are allowed up for only an hour or two daily, and are not encouraged to take exercise; then this period is gradually lengthened and more freedom permitted; and, finally, when they are up for half a day or more they have exercises, games, dancing, etc., and are gradually brought to resume the normal activities of a healthy child. 
The following are the points on which most stress is laid in assessing the progress of the case and deciding the rate at which progressive stages of the treatment can with safety be adopted. If there is a history that the patient has had a recent attack of what is undoubtedly rheumatism, and the heart is either undamaged or there is only a soft systolic murmur present at the apex, then a prolonged period of rest in bed is indicated. If the patient has had repeated rheumatic attacks and the heart is obviously enlarged and damaged, or if, as sometimes occurs, the heart has remained normal in spite of repeated attacks of rheumatism or chorea, then it would seem best to prolong the convalescent period of the treatment, and to reduce or to a large extent omit the period of absolute rest. The pulse is a valuable guide to the progress of the case. The pulse rate is recorded as a routine measure night and morning and at 2 p.m., and, if necessary, more frequently. If all has gone well during the period of rest the morning and evening pulse rates are about the same. When the patient begins to get up there is, as a rule, a slight rise, more especially of the evening pulse rate; but if the progress of the case has been satisfactory the rate should not be much over 100 , and should tend to settle. It must, however, be remembered that there is a considerable degree of variation in the pulse rate of children, and in some cases a pulse rate of 120 or over goes with what appears to be a healthy heart; but as a rule a raised pulse rate, occurring as the result of the very gradual increase in activity that is allowed, must be taken as a danger signal. In cases where the pulse rate settles slowly or is easily raised it is considered best to retard the transfer to the convalescent wards. The temperature almost always settles very shortly after admission, and prolonged pyrexia is so rare that it is of little value as a guide in the general management of the treatment. The erythrocyte sedimentation test is also of value, a raised rate being almost always indicative of activity, if other infective conditions can be excluded. Unfortunately the test fails in cases of chorea. Nevertheless, in spite of these limitations, two years' experience of the routine use of the test at two of the units has afforded proof of its value in assessing the activity of the rheumatic infection.

Education.-The essential function of a rheumatism unit is of course to give the rheumatic child the prolonged treatment and nursing the disease requires, but ancillary to this is the 
provision of facilities for education during the later stages of the treatment. If the children are to be kept at rest for any prolonged period, it is essential that they should be kept occupied, otherwise they become dull and irritable and the whole object of the treatment is frustrated. It is therefore a most valuable adjunct to treatment to have school work carried on in the wards, and the individuality of the teacher is a point of no mean importance. Moreover, a certain amount of suitably planned education provides that necessary mental background which enables the child to renounce gradually and naturally the rôle of invalid, and when discharged from hospital to re-enter the ordinary school world without any great or sudden change in its mode of life. Provision for education is therefore made in all the Council's rheumatism units which are recognised as "hospital schools" by the Board of Education. On the whole, the rheumatic children seem to be bright and eager, though all types of intellect are met with among them. They are, however, often backward owing to having lost time at school on account of ill-health. With suitable training they nearly all regain lost ground, and they certainly enjoy their lessons and feel something lost out of the day during the periods that are designated holidays. It seems advisable that there should be as few of these arbitrary breaks in the school work as possible. During the periods the patients spend in hospital they must, for various reasons, lose a certain number of school days, so that there is little danger of their being over-driven, and there seems little reason, so far as the children are concerned, why the formal holidays should be adhered to. It is only possible to carry out a limited amount of manual work, but towards the end of their stay in hospital a certain amount of simple handicraft is done, and all through the period most of the girls do knitting and needlework.

DIET.-The diet the rheumatic children receive is an ample but very simple one. It would seem that the hospital diet is much richer in both calcium and animal fats than that which most of them receive when in their own homes. Certain writers have commented upon the fact that rheumatic children tend to have a marked aversion to milk and a craving for strong-tasting acid types of food, such as vinegar, pickles and sauces. These idiosyncrasies are almost unknown in the rheumatism wards, and although occasionally there are children who do not care 
for milk, there have been few who would not take it, and so far as fads and peculiarities of diet are concerned, the rheumatic children seem to differ in no way from other patients. It must, of course, be remembered that very few of the rheumatic patients show clinical evidence of acute rheumatism for more than a week or two after admission, and it may be that it is while the disease is in the more active stage that the child tends to shun certain articles of diet. During the more acute stages of the disease rheumatic children tend to lose weight rapidly, but as soon as convalescence is reached they quickly regain this loss.

HELIOTHERAPY.-During the summer months the rheumatic children are freely exposed to the natural sunlight, and just the customary precautions are taken to prevent actual sunburn or too prolonged exposure to the hot midday sun. Most of the patients pigment well, but their skin reactions seem to be very much as those of other patients. During the winter months artificial actinotherapy is employed, but only to a limited extent, as only those patients who are allowed to be out of bed can be treated. Carbon arc lamps are used, and at Queen Mary's Hospital, Carshalton, the child receives each week two or three light baths of about an hour's duration. It is very difficult to assess the value of light treatment. It would seem that its influence is not very marked, but on the whole it would appear to be beneficial and very pleasing to the children.

DRUGS.-Of the numerous drugs which have from time to time been tried, only the salicylates have remained persistently popular. Drugs of the sulphonamide group are now being given a trial, but it is yet too early to assess their value. Recently American authorities have published encouraging reports.

Artifictal Pyrexia.-Our experience of the results obtained by this method of treating chorea have been disappointing.

Clothing.- The view is very generally held that rheumatic children require rather special protection against the weather, and the advisability of wearing warm woollen underclothing and the danger of allowing rheumatic children to go about in shorts and other forms of dress that do not adequately protect the knees have been stressed by many writers. Also, it is the common teaching that rheumatic patients, when in bed, should be nursed between blankets. It would seem that there is very little foundation for these traditional beliefs. During the summer months the clothing of the rheumatic children is reduced to the very mini- 
mum, and as a result of this they become very hardy and are in no hurry to resume their heavier clothing when in autumn the days become colder, and yet the recurrence of any rheumatic manifestations while the patients are in hospital is extremely rare. During the winter months the children are warmly clad, but many of the boys wear jerseys and shorts that leave the knees uncovered, and they seem to suffer in no way from this. The children are provided with overcoats, but, except on the very coldest days, they seem to prefer to be without them. Colds and intercurrent infections do occur, but they are not common, and as a rule the children throw them off easily, and so far as rheumatism is concerned relapses are very rare, and such vague conditions as "growing-pains" are almost unknown in the convalescent wards. Although all the rheumatic patients when first admitted are nursed in the wards, quite a large proportion of the convalescent cases sleep out under glass verandahs, even during the winter months. Also, unless the weather is very unsettled or it is actually raining, the beds are taken from the wards into the open courtyards daily during both summer and winter months. The result of all this fresh air and exposure seems to be highly beneficial.

In conclusion it may be said that rest under good hygienic conditions, with a very gradual return to the normal activities of life, is the basis of the treatment of juvenile rheumatic patients. The results are fairly successful, but the treatment has the inherent disadvantage of being lengthy and expensive, and has the obvious disadvantage of keeping children away from their homes for long periods. Any steps that could be taken to shorten the duration of the treatment or make more certain the immunity from relapses would be of the greatest value. Up to the present no specific treatment has been found.

TonsiLlectomy.-The value of tonsillectomy as a method of preventing recurrences in cases of juvenile rheumatism or of warding off the cardiac complications has, in the past, been widely debated.

Very differing views are held by observers as to the part played by the tonsils in the ætiology and prognosis of rheumatic disease in children. Analyses in this connection are beset with difficulties. Unless very small numbers are considered (and this may result in deductions being vitiated by elementary statistical fallacies) there is always the possibility of errors being introduced 
owing to incomplete information in case notes " written up " by many different observers. Also, clinicians often differ considerably as to the standards they adopt in describing a tonsillectomy as "complete" and "satisfactory." Even more do differing standards influence case records when it is a matter of assessing whether cardiac damage is severe and progressive or slight and unimportant. These difficulties have not been absent in the analyses from which the figures tabulated below are derived.

Since bacteriological investigations had shown that hæmolytic streptococci were frequently present in the throats of children whose tonsils were chronically enlarged or inflamed, it was an obvious suggestion that removal of the tonsils should be a useful means of preventing the development of rheumatism in such children. The following analysis of cases treated under the London County Council's Rheumatism Scheme would seem to negative the soundness of this view:

Results of Analysis of 1,500 Cases of JUVenile Rheumatism adm itTed TO THE COUNCII's RHEUMATISM UNITS with REFERENCE to the CoNDITION OF THE TONSILS

Number in whom tonsils had been removed prior to first known

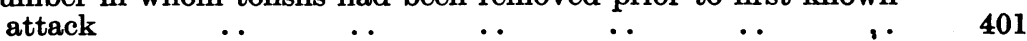

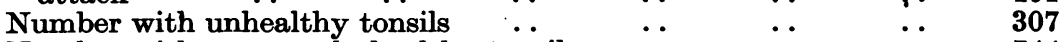

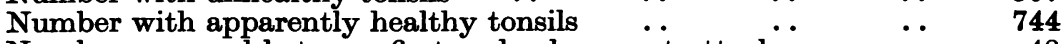
Number removed between first and subsequent attacks $\quad \ldots \quad 48$

$$
\begin{array}{lllllll}
\text { Total } & \ldots & \ldots & \ldots & \ldots & \ldots & 1,500
\end{array}
$$

Of significance also in this connection are the statistics relating to the number of tonsillectomies performed on London elementary school children. The number gradually rose from 7,656 in 1923 to 18,178 in 1931 , and subsequently began to diminish. In fact, in 1931 the School Medical Officer estimated that one-third of London elementary school children had had their tonsils removed. Figures taken from the Annual Report of the Chief Medical Officer of the Board of Education indicate that about 50 per cent. of tonsillectomies are done on children between the ages of five and seven years inclusive. This period lies below the age of greatest incidence of juvenile rheumatism, and if the operation had any prophylactic value it would be reasonable to suppose that from 1931 onwards a sensible diminution in the incidence of juvenile rheumatism should be beginning to show itself; but there is no evidence of this, as the following figures show: 
Number of nominations for insti-

1932.1933 .1934 .1935 .1936$. tutional treatment under the

$\begin{array}{llllllll}\text { Council's scheme } & \ldots & \ldots & 1,234 & 1,845 & 1,571 & 1,703 & 1,719\end{array}$

(Note.-The 1935 and 1936 figures have been corrected to allow for certain administrative changes in the scheme.)

From the facts shown in the above tables it would seem to be reasonably certain that there is no statistical evidence pointing to the value of tonsillectomy as a means of preventing the occurrence of rheumatic infection, and one must conclude that if a hæmolytic streptococcus be the cause, unhealthy tonsillar or naso-pharyngeal lymphoid tissue is by no means a necessary factor in affording admission to the organism; nor does the removal of such tissue afford protection.

When, however, the severity of the attack was considered in conjunction with the condition of the tonsils, some interesting and suggestive figures were obtained. In considering the ætiology of juvenile rheumatism it was pointed out that in a series of 1,000 admissions to the rheumatism units in fifty-three instances the attack was preceded by a definite tonsillitis. An analysis of these figures showed that the general incidence of cardiac damage in the complete series amounted to 36 per cent., whereas in those cases where the attack was preceded by a tonsillitis the incidence of permanent cardiac damage was 70 per cent.

The subjoined tables also supply some interesting figures:

Table VII.-Comparison of the INCIDENCE OF the More SeVere aNd

Progressive Cardiac Complications in Rheumatic Chitdoren

WHOSE TONSILS HAVE BEEN REMOVED WITH THE INCIDENCE IN

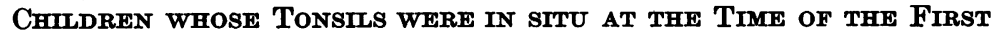

AtTack of Rheumatism

(Figures from case records of children treated at Queen Mary's Hospital, Carshalton.)

\begin{tabular}{c|c|c|c|c|c}
\hline & \multicolumn{4}{|c}{ Cardiac Condition. } \\
\cline { 2 - 5 } $\begin{array}{c}\text { Condition of } \\
\text { Tonsillar Region. }\end{array}$ & $\begin{array}{c}\text { Total } \\
\text { Number. }\end{array}$ & $\begin{array}{c}\text { Normal and } \\
\text { Indefinite } \\
\text { "Murmurs." }\end{array}$ & $\begin{array}{c}\text { Mitral Stenosis, } \\
\text { Mitral and/or } \\
\text { Aortic Disease. }\end{array}$ \\
\cline { 2 - 5 } & Number. & $\begin{array}{c}\text { Per. } \\
\text { centage. }\end{array}$ & Number. & $\begin{array}{c}\text { Per. } \\
\text { centage. }\end{array}$ \\
\hline $\begin{array}{c}\text { Tonsils not removed } \\
\text { before onset .. } \\
\text { Tonsils satisfactor- } \\
\text { ily removed be- } \\
\text { fore onset }\end{array}$ & 716 & 492 & $68 \cdot 6$ & 224 & $31 \cdot 4$ \\
\hline
\end{tabular}


It is seen that the children who had not had tonsillectomy performed showed an increase of 8.7 per cent. in the incidence of severe cardiac involvement as compared with the incidence in children who had had the operation.

A similar analysis was made of 1,500 cases admitted to the rheumatism units during the first half of 1937 :

TABLE VIII

\begin{tabular}{|c|c|c|c|c|c|}
\hline \multirow{3}{*}{$\begin{array}{c}\text { Condition of } \\
\text { Tonsillar Region. }\end{array}$} & \multirow{3}{*}{$\begin{array}{c}\text { Total } \\
\text { Number. }\end{array}$} & \multicolumn{4}{|c|}{ Cardiac Condition. } \\
\hline & & \multicolumn{2}{|c|}{$\begin{array}{l}\text { Normal or } \\
\text { Indefinite } \\
\text { “ Murmurs." }\end{array}$} & \multicolumn{2}{|c|}{$\begin{array}{c}\text { Mitral Stenosis, } \\
\text { Mitral and/or } \\
\text { Aortic Disease. }\end{array}$} \\
\hline & & Number. & $\begin{array}{c}\text { Per- } \\
\text { centage. }\end{array}$ & Number. & $\begin{array}{c}\text { Per- } \\
\text { centage. }\end{array}$ \\
\hline $\begin{array}{c}\text { Tonsils not re- } \\
\text { moved before } \\
\text { onset } \\
\text { Tonsils satisfactor- } \\
\text { ily removed be- } \\
\text { fore onset }\end{array}$ & 1,099 & 828 & $75 \cdot 4$ & 271 & $24 \cdot 6$ \\
\hline
\end{tabular}

In this table the difference between the percentage incidence of severe cardiac disease in the two groups is reduced to $5 \cdot 7$ per cent. as compared with the figures taken from the Queen Mary's Hospital records.

It is evident that the value of early tonsillectomy, with a view to preventing the occurrence of severe cardiac involvement, is a subject well worth further study, and the results of such an investigation might profoundly affect our conceptions as to the periods of institutional treatment required. Up to the present a very cautious attitude has prevailed in the matter of advising tonsillectomy, and the operation has been performed only when the tonsils were obviously grossly diseased and the rheumatic infection apparently quiescent. This conservative view may have to be modified as a result of further research.

The results of a Rheumatism Scheme must be chiefly judged by the measure of its success in reducing the incidence of the cardiac sequelæ of rheumatism, especially the incidence of permanent cardiac damage. In very few cases is a rheumatic attack unaccompanied by signs indicating the presence of a carditis. If, however, this can be induced to subside without permanent 
valvular or myocardial damage no great harm is done. This, then, is the essential problem which has to be solved. With chronic and insidious diseases where no specific treatment is known it is always a difficult matter to prove that treatment on general lines is beneficial, and a true appreciation of its results can usually only be arrived at by a consideration of indirect evidence and by patient observation extending over many years. One method of assessing the results attained by the London County Council's Rheumatism Scheme is to ascertain if there has been any decrease in the incidence of rheumatic cardiac disease in London school children since the inception of the scheme. The figures given in the following table are suggestive:

Table IX.-Percentages of Elementary School Children found by School Doctors to be suffering from Cardiac Disease

\begin{tabular}{c|c|c|c} 
Year. & $\begin{array}{c}\text { Number of Children } \\
\text { examined by } \\
\text { School Doctors. }\end{array}$ & $\begin{array}{c}\text { Number with } \\
\text { Acquired Cardiac } \\
\text { Disease. }\end{array}$ & Percentage. \\
\hline 1923 & 236,658 & 5,011 & $2 \cdot 1$ \\
1924 & 234,233 & 5,231 & $2 \cdot 2$ \\
1925 & 281,595 & 5,952 & $2 \cdot 1$ \\
1926 & 285,548 & 5,676 & $2 \cdot 0$ \\
$1927 *$ & 292,202 & 5,629 & $1 \cdot 9$ \\
1928 & 304,206 & 5,872 & $1 \cdot 9$ \\
1929 & 283,250 & 5,441 & $1 \cdot 9$ \\
1930 & 253,656 & 4,667 & $1 \cdot 8$ \\
1931 & 309,247 & 3,723 & $1 \cdot 2$ \\
1932 & 315,880 & 3,868 & $1 \cdot 2$ \\
1933 & 304,014 & 3,852 & $1 \cdot 2$ \\
1934 & 297,801 & 3,845 & 0.3 \\
1935 & 316,567 & 3,077 & $0 \cdot 9$ \\
1936 & 301,392 & 2,648 & $0 \cdot 77$ \\
1937 & 314,959 & 2,431 &
\end{tabular}

* Council's Rheumatism Scheme came into operation.

It will be noted a decrease of over 50 per cent. has occurred during the ten years the scheme has been in operation, and though it might be claiming too much to attribute the whole of this decrease to the effects of the scheme, it is not unreasonable to assume that it may claim some of the credit.

SUBSIDENCE OF CARDITIS.-In an analysis of 1,094 unselected cases discharged from the units in 1934, the fact was revealed that of the 600 who showed signs of cardiac involvement on admission, 149 (i.e., nearly 25 per cent. of the number) had no signs of cardiac disease on discharge. Even allowing for the possibilities of observational variations the figures seem to afford striking evidence of the value of prolonged rest. Furthermore, 
of the 494 cases without cardiac complications on admission, only ten developed signs of cardiac involvement whilst in hospital, and seven of these were of a very mild or doubtful type. There would certainly appear to be little risk of cardiac valvular disease developing if the child can be given complete rest in good surroundings at the onset of the disease.

Ultimate Prognosis.-In order to arrive at some precise conclusion if possible as to the ultimate results in cases of juvenile rheumatism two groups, each consisting of 200 children, were studied. The first group consisted of children admitted to Queen Mary's Hospital during 1927. The second group was made up of children admitted in 1932. In the classification of the present condition of those still living, those who are now able to carry out their ordinary employment or attend their usual school have been classified as "alive and well," unless records show that they are carrying on their employment in spite of being crippled by heart disease. Those who are only fit to undertake light work or to receive education in a school for physically defective children, together with those who are known to be unfit for any form of occupation, have been classed under the heading "Invalided."

Unfortunately it was only possible to trace 242 of the 400 cases under review. An analysis of these cases was made in connection with the age of onset of the disease, and the results are summarised in the table given previously (Table I., p. 215). In the following table (Table X.) the 242 cases traced are classified according to the condition of the heart on admission, and the table summarises the ultimate outcome. As the numbers are only small, it was thought best to summarise the findings in a single table.

Table X.-Condition in 1937 of 240 Rheumatic Children grouped according to the Cardiac Lesion Present

\begin{tabular}{|c|c|c|c|}
\hline $\begin{array}{l}\text { Condition of Heart } \\
\text { on Admission. }\end{array}$ & $\begin{array}{c}\text { Percentage } \\
\text { Alive and } \\
\text { Well. }\end{array}$ & $\begin{array}{l}\text { Percentage } \\
\text { of Invalids. }\end{array}$ & $\begin{array}{l}\text { Percentage } \\
\text { Deceased. }\end{array}$ \\
\hline \multirow{5}{*}{$\begin{array}{l}\text { No evidence of cardiac disease } \\
\text { Disease of mitral valve with- } \\
\text { out stenosis } \\
\text { Disease of mitral valve with } \\
\text { stenosis } \\
\text { Disease of aortic valve only } \\
\text { Disease of both mitral and } \\
\text { aortic valves .. }\end{array}$} & $80 \cdot 0$ & $17 \cdot 5$ & $2 \cdot 5$ \\
\hline & $66^{\circ} 0$ & $22 \cdot 5$ & $11 \cdot 5$ \\
\hline & $37 \cdot 7$ & $27 \cdot 5$ & $\mathbf{3 4} \cdot 8$ \\
\hline & \multicolumn{3}{|c|}{ Only one case traced (alive and well) } \\
\hline & $9 \cdot 0$ & $9 \cdot 0$ & $82 \cdot 0$ \\
\hline
\end{tabular}


From the preceding table it is seen that those admitted with extensive valvular lesions and evidence of mitral stenosis have, on the whole, done badly, and few of them can be classified as " alive and well." On the other hand, those that were admitted with no definite evidence of carditis or with only a systolic murmur in the mitral area have, with few exceptions, made a satisfactory recovery. Of the sixty-nine children showing signs of mitral stenosis who have been followed up, forty-three are either dead or invalided. On the other hand, sixty-two children with only slight mitral involvement have been traced, and of them forty-one are alive and well and only twenty-one dead or invalided.

\section{Summary aNd SUgGestions}

(1) At the present time the immediate causation of juvenile rheumatism and the factors conducive to its occurrence are still imperfectly known, and until research is carried further no advance in the direction of prevention or treatment is probable.

(2) Following the more intensive supervision of school children during recent years, insidious rheumatism and carditis are discovered at an earlier stage, and admissions to the rheumatic units during the last three years have shown a distinctly milder type of cardiac involvement. The Rheumatism Supervisory Centres which have been established as part of the Council's Rheumatism Scheme carry out most essential work in this connection.

(3) During the eleven years which have elapsed since the inception of the Rheumatism Scheme a notable fall has occurred in the incidence of rheumatic heart disease in London school children.

(4) Up to the present time the treatment for juvenile rheumatism has been based on prolonged rest. It may be that further investigation of its ætiology will modify our views as to the length of time necessary for adequate treatment. If this period could be shortened it would be of much value in the matter of freeing beds for acute cases. In this connection studies should be made of the effect of early tonsillectomy on the prevention of the severer cardiac complications and of the influence of diet on the occurrence of juvenile rheumatism. A fuller investigation of the relationship of the disease to social conditions is also very 
desirable, and an endeavour to elucidate the part played by hereditary influences might add much to our knowledge.

So far as drug treatment is concerned, no drug has yet been found which gives any better results than are obtained by the use of salicylates.

(5) It seems evident that more extensive provision for research on general questions relating to the incidence of juvenile rheumatism is urgently required, and that qualified research workers should be appointed for this purpose.

(6) The importance of careful selection of the medical and nursing staff cannot be overestimated. Doctors and nurses who show special aptitude for dealing with rheumatic cases should be encouraged and their services retained.

(7) Both from the point of view of the interests of the patients and the facilitation of research, cases should be transferred to special rheumatism units in the early acute stages of the disease. Too often, at present, are such patients retained in mixed general wards in town hospitals for considerable periods.

(8) It is a matter for regret that schemes for the treatment of juvenile rheumatism are at present applicable only to children under the age of sixteen. This precludes the supervision and treatment of many young adults. It also renders impossible the adequate following-up into adult life of the greater proportion of the juvenile cases. Advice in connection with suitable and unsuitable occupations, child-bearing, and general regimen is at present not readily accessible, and this fact is directly responsible for much chronic invalidism and reduced expectation of life. Supervisory clinics for young adults on similar lines to those available for children would be well worth their cost.

\section{APPENDIX I}

Approximate Cost per Annum of Treatment and Special Education of Rheumatic Children in London

Annual cost of treatment and education of children in rheumatism units .. $\quad . . \quad \ldots . \quad \ldots \quad \ldots$

Annual cost of Rheumatism Supervisory Centres .. $\quad \ldots . \quad 1,850$

Employment of consultants for special reports $\ldots . \quad \ldots \quad 900$

Estimated extra cost of rheumatic children attending day

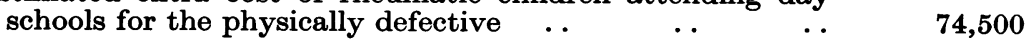

Total annual cost

$$
\text { spect of maintenance }
$$

Less contributions from relatives in respect of maintenance

in the special hospitals

$$
\begin{array}{llllll}
\text { Net annual cost } \ldots & \ldots & \ldots & \ldots & \ldots & £ 202,050
\end{array}
$$


The London County Council is not called upon to find the whole of this amount, since, for children attending schools for the physically defective and for those under treatment in the rheumatism units which are recognised as hospital schools, the Council receives a grant from the Board of Education equal to 50 per cent. of the expenditure incurred.

\section{APPENDIX II}

Provision for the Treatment and Supervision of Rheumatic Disease in London ChildRen apart from that MADE BY THE COUNCIL

(1) Provision by Voluntary Hospitals.-Large numbers of rheumatic children are treated annually both as in-patients and out-patients at the London voluntary hospitals. Figures relating to the number of rheumatic children treated as inpatients during 1936 were supplied through the courtesy of the respective secretaries of the following children's hospitals:

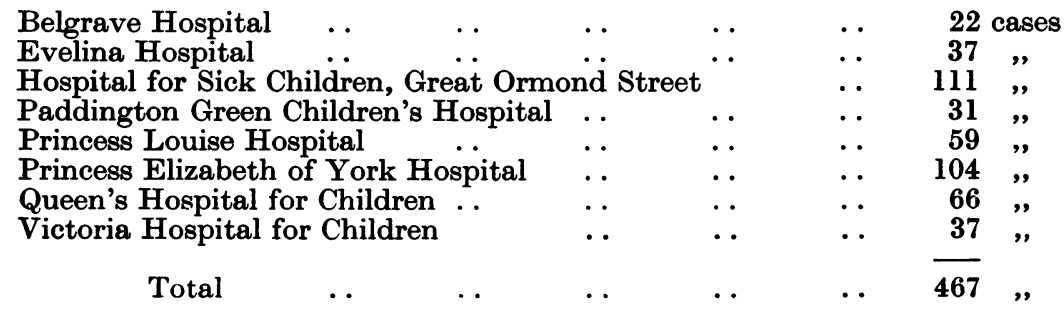

In addition, of course, many children are treated in voluntary hospitals not especially reserved for children.

(2) Heart Homes and Hospital Schools other than the Council's Rheumatism UNITS:

(a) Provided by the Invalid Children's Aid Association: West Wickham Heart Home

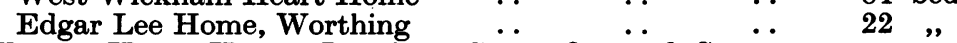

(b) Warren Heart Home, Lancing (Great Ormond Street Hospital)

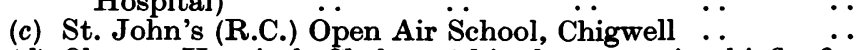

(d) Cheyne Hospital, Chelsea (this, however, is chiefly for children from Surrey) $\ldots \quad$.. $\quad . . \quad \ldots$ $\begin{array}{lllllll}\text { Total } & \ldots & \ldots & \ldots & \ldots & \ldots & \overline{233}\end{array}$

(3) Borough Rheumatism Supervisory Centres.-In the Royal Borough of Kensington and in the Borough of Paddington 
Rheumatism Supervisory Centres have been established in connection with the public health services under the control of the respective Borough Medical Officers of Health.

(4) Notification.-In London acute rheumatism is compulsorily notifiable in the following boroughs: Holborn, Paddington, the Royal Borough of Kensington.

For permission to use the material embodied in this paper the authors are indebted to Sir Frederick Menzies, K.B.E., M.D., F.R.C.P., F.R.S. (Edin.), Medical Officer of the London County Council.

In order to comply with the Standing Orders of the Council it is necessary to state that the Council accepts no responsibility for any opinion or conclusion expressed in this article. 